\title{
Low reliability of the Risser sign in consecutive radiographs: a case series
}

\author{
Stefano Negrini", Salvatore Atanasio, Sabrina Donzelli, Monia Lusini, Salvatore Minnella, Francesco Negrini, \\ Fabio Zaina \\ From 10th International Conference on Conservative Management of Spinal Deformities - SOSORT 2013 \\ Annual Meeting \\ Chicago, IL, USA. 8-11 May 2013
}

\section{Background}

The low reliability of the Risser sign has been described in previous studies; however, the test/retest reliability of the Risser sign in different radiographs has not been examined or reported.

\section{Purpose}

The goal of this report was to present data collected from studying a group of adolescent idiopathic scoliosis (AIS) patients whose Risser sign decreased in two consecutive $\mathrm{X}$ rays.

\section{Methods}

Case series using the European Risser test.

\section{Results}

By chance, a reduction of the Risser test was discovered in one patient. Subsequently, other cases have been searched to see if this was an exceptional situation. In one year, we found three more cases.

\section{Conclusions and discussion}

At this stage, the following explanatory hypotheses can be drawn:

Technical radiological differences (exposure, machine)

Variation of pelvis positioning

Postural changes influencing the pelvis

Brace compression on the pelvis

According to our study results, all of the hypotheses include data both in favor and against the reliability of the Risser sign. Since the Risser sign is a $2 \mathrm{D}$ evaluation

* Correspondence: stefano.negrini@isico.it

University of Brescia - IRCCS Don Gnocchi, Milan, Italy
Table 1

\begin{tabular}{lllll}
\hline & 1 & 2 & 3 & 4 \\
\hline Age & 16.1 & 14.8 & 14.4 & 15.9 \\
Height $(\mathrm{cm})$ & 0 & +1 & +1.5 & 0 \\
Weight $(\mathrm{kg})$ & +1 & 0 & +1.5 & 0 \\
Risser & 4 to 2 & 1 to 0 & 2 to 1 & 4 to 3 \\
Brace & Sforzesco & PASB & SpineCor & Sforzesco \\
Hours/day & 23 & 12 & 20 & 16 \\
Bracing months & 4 & 6 & 4 & 22 \\
Months between x-rays & 7 & 6 & 6 & 14 \\
In brace x-ray & No & No & Yes & No \\
Change of x-ray machine & No & No & Yes & Yes \\
${ }^{\circ}$ Cobb & -23 & -4 & -7 & +4 \\
Change of rotation of the & ++ & + & $?$ & + \\
pelvis & & & & \\
C7+L3 distance $(\mathrm{cm})$ & -3 & 0 & +0.5 & -0.5 \\
ATR $\left(^{\circ}\right)$ & -8 & -3 & -3 & +3 \\
\hline
\end{tabular}

of a 3D phenomenon, pelvis repositioning could perhaps be the most plausible explanation.

This case series is open to the possibility that the Risser sign is even less reliable than originally considered. Unfortunately, this result cannot be checked experimentally due to ethical reasons. Nevertheless, observational designs could be considered in the future.

Published: 18 September 2013

\section{References}

1. Hammond KE, Dierckman BD, Burnworth L, Meehan PL, Oswald TS: Interobserver and intra-observer reliability of the Risser sign in a metropolitan scoliosis screening program. J Pediatr Orthop 2011, 31(8): e80-e84

2. Kotwicki T: Improved accuracy in Risser sign grading with lateral spinal radiography. Eur Spine J 2008, 17(12):1676-1685. 
3. Reem J, Carney J, Stanley M, Cassidy J: Risser sign inter-rater and intrarater agreement: is the Risser sign reliable? Skeletal Radiol 2009, 38(4):371-375.

doi:10.1186/1748-7161-8-S2-018

Cite this article as: Negrini et al:: Low reliability of the Risser sign in consecutive radiographs: a case series. Scoliosis 2013 8(Suppl 2):O18.

Submit your next manuscript to BioMed Central and take full advantage of:

- Convenient online submission

- Thorough peer review

- No space constraints or color figure charges

- Immediate publication on acceptance

- Inclusion in PubMed, CAS, Scopus and Google Scholar

- Research which is freely available for redistribution

Submit your manuscript at www.biomedcentral.com/submit
C Biomed Central 